\title{
BRINQUEDOS E JOGOS TRADICIONAIS DA TRIFRONTEIRA
}

\author{
Recebido em: 09/01/2018 \\ Aceito em: 27/11/2018 \\ Cícera Andréia de Souza ${ }^{1}$ \\ Bianca Teles de Moura ${ }^{2}$ \\ Luciano Gularte de Lima \\ Instituto Federal do Paraná - IFPR - Campus Avançado Barracão \\ Barracão - PR - Brasil \\ Danieli Maehler Nejeliski ${ }^{3}$ \\ Instituto Federal Sul-rio-grandense - Campus Pelotas \\ Pelotas - RS - Brasil
}

RESUMO: O presente estudo tem como objetivo apresentar os resultados de uma investigação acerca dos brinquedos e jogos tradicionais da Trifronteira (Dionísio Cerqueira-SC, Barracão-PR e Bernardo de Irigoyen-AR) no período da fundação das três cidades, entre os anos 1950 e 1960. A pesquisa foi desenvolvida através de entrevistas semiestruturadas realizadas com 33 pessoas (10 do sexo masculino e 23 do sexo feminino) com idade igual ou superior a 55 anos, que viveram a infância no referido período e local. Como resultado, os brinquedos mais citados foram a boneca de pano e o carrinho de descida. Com relação à produção, constatou-se que $86 \%$ dos brinquedos eram produzidos artesanalmente com as ferramentas disponíveis e com resíduos das atividades realizadas nos espaços de trabalho em casa. Com relação aos jogos, destacaram-se a peteca, esconde-esconde e caçador, muito praticados no turno inverso a escola, ao ar livre.

PALAVRAS CHAVE: Brinquedos Tradicionais. Jogos Tradicionais. Trifronteira.

\section{TRADITIONAL TRI BORDER TOYS AND GAMES}

ABSTRACT: This study aims to present the results of an investigation about to traditional toys and games at Tri Border (Dionísio Cerqueira-SC, Barracão-PR and Bernardo de Irigoyen-AR) during the foundation of the three cities, between the $1950 \mathrm{~s}$ and 1960s. Research was conducted through an interview with 33 people (10 males and 23 females) aged 55 years or over who lived their childhood in that period and place. As a result, the most cited toys were the cloth doll and the cart. Regarding

\footnotetext{
${ }^{1}$ Mestra em Educação Física pela UFSM, especialista em Educação Física Escolar - UFSM, graduada em Educação Física Plena - UFSM, professora do Ensino Básico, Técnico e Tecnológico no Instituto Federal do Paraná - IFPR, Campus Avançado Barracão.

${ }^{2}$ Estudante do Curso Técnico em Administração integrado ao Ensino Médio, IFPR, Campus Avançado Barracão.

${ }^{3}$ Mestra em Design pela UFRGS, graduada em Desenho Industrial com habilitação em Projeto de Produto pela UFSM, professora do Ensino Básico, Técnico e Tecnológico no Instituto Federal Sul-riograndense, Campus Pelotas.
} 
production, it was found that $86 \%$ of the toys were produced by hand with the tools available and with residues of the activities carried out in the work spaces at home. Regarding the games, the peteca, hide-and-seek and hunter stood out, much practiced in the inverse shift to school, in the open air.

KEYWORDS: Traditional Toys. Traditional Games. Tri-Border.

\section{Introdução}

O esporte como fenômeno mundial tem se tornado dia-a-dia uma prática corporal supervalorizada. Em contrapartida outras práticas como as brincadeiras e os jogos tradicionais vêm sendo esquecidas, substituídas. $\mathrm{O}$ brinquedo é um objeto utilizado para designar o sentido do brincar, construído pelo homem com significações de acordo com a época, a cultura e o contexto (FRIEDMANN, 1996). Já os jogos são atividades submetidas a um sistema de regras que define a estrutura e o modo de funcionamento da atividade (MARIN, E. C. et al., 2012). Concordamos com Cascudo (1984) e Kishimoto (1999) ao compreender que as brincadeiras e os jogos tradicionais fazem parte da cultura popular e é expressão da história transmitida através da oralidade.

Marin et al. (2012) destacam que os jogos tradicionais vêm sendo substituídos por outros que tem como interesse a alta lucratividade, como os jogos eletrônicos. No mesmo sentido, Kunz e Costa (2015) destacam que o mundo tecnologizado e a falta de espaços físicos tem feito com que as crianças tenham menos possibilidades para brincar ao ar livre. Franchi (2013) entende que a perda da prática das brincadeiras e jogos tradicionais implica no esquecimento e na perda de valores culturais construídos através dessas práticas.

A consciência da importância do resgate dos brinquedos, brincadeiras e jogos tradicionais não é recente. Em 1978 as práticas de brincar e jogar foram reconhecidos pela UNESCO como patrimônio cultural da humanidade. Em 1999, na terceira 
Conferência Internacional de Ministros e Altos Funcionários encarregados pela Educação Física e pelo Esporte, foi formulada uma declaração que buscou apoiar uma política de conservação e valorização dos jogos tradicionais (LAVEGA, 2013). Hoje vemos um crescimento de estudos na área, mas ainda de modo pouco expressivo.

No sentido de contribuir para com os estudos desse campo, o presente trabalho teve como objetivo investigar as práticas corporais relacionadas ao brincar e ao jogo tradicional no período da fundação das cidades da Trifronteira (Barracão-PR, Dionísio Cerqueira-SC e Bernardo de Irigoyen-AR), após a constatação de ausência de estudos sobre essa temática neste local. Concordamos com Elkonin (1998) quando este se contrapõe a ideia de estudar as brincadeiras ou os jogos de forma fragmentada, sem compreender a totalidade entre indivíduo e sociedade. Para tanto, procuramos conhecer a realidade da sociedade investigada sendo essa peculiar por tratar-se de três municípios, dois brasileiros e um argentino, que convivem diariamente devido à proximidade geográfica.

Conhecida como "Trifronteira" a região que engloba as cidades de Barracão Paraná/Brasil, Dionísio Cerqueira - Santa Catarina/Brasil e Bernardo de Irigoyen Misiones/Argentina, é uma região de fronteira seca que reúne três cidades, dois estados e dois países. Juntas estas cidades possuem cerca de 45 mil habitantes e compartilham além da economia, costumes e tradições. A proximidade geográfica é tanta que é possível atravessar a rua e estar em outra cidade, outro estado e até mesmo em outro país. Sendo assim, faz sentido a investigação das três cidades e não apenas de uma delas.

Andar pelas ruas de Barracão, Dionísio Cerqueira e Bernardo de Irigoyen é estar em muitos momentos perdendo o sentido geográfico, pois as cidades se entrelaçam numa trama urbana sobre o ziguezague dos limites político-territoriais internacionais, estaduais e municipais (FERRARI, 2010, p.282). 
A Trifronteira teve sua ocupação produtiva tardia. Segundo Ferrari (2010) a região fronteiriça não oferecia as condições naturais para o cultivo de produtos exigidos pelas metrópoles colonizadoras o que fez com que sua colonização produtiva acontecesse tardiamente. Um maior desenvolvimento e colonização da região só vieram a ocorrer com a emancipação de Barracão em 1951 e com a emancipação de Dionísio Cerqueira em 1953. Nesse período a região recebeu um grande número de migrantes vindos, principalmente do Rio Grande do Sul. Esses migrantes trouxeram e desenvolveram no local práticas laborais voltadas à agricultura e a produção de animais, especialmente a criação de suínos. Além disso, também trouxeram consigo práticas corporais como brincadeiras e jogos que acabaram por se tornar práticas corporais características do local no período. Resgatar estas práticas significa resgatar a história e os valores culturais não somente do lugar, mas também das pessoas que aqui viveram-vivem, com isso é possível fortalecer a questão de pertencimento local, como também favorecer a troca de saberes entre gerações.

\section{Métodos}

O presente trabalho apresenta resultados de um estudo de caso, definido por Triviños (2012, p.133) como sendo “(...) uma categoria de pesquisa cujo objeto é uma unidade que se analisa profundamente", desse modo os objetos pesquisados são os brinquedos, brincadeiras e jogos tradicionais presentes na cultura infantil de pessoas com 55 anos ou mais que viveram a infância na Trifronteira. Para tanto, entrevistou-se 33 pessoas (43\% de Barracão-PR; 33\% de Dionísio Cerqueira-SC; 24\% de Bernardo de Irigoyen-AR) sendo 10 pessoas do sexo masculino e 23 pessoas do sexo feminino. As entrevistas foram realizadas em dois lugares, primeiro no Centro de Convivência de Idosos Raio de Luz em Barracão-PR e depois no Centro de Convivência de Idosos 
de Dionísio Cerqueira-SC. Como Bernardo de Irigoyen não possui local de convivência de idosos, os argentinos entrevistados foram aqueles encontrados nos centros de convivência de Barracão e Dionísio Cerqueira.

Para a coleta de dados, os sujeitos pesquisados responderam a uma entrevista semiestruturada sobre a temática e objetivo do estudo, adaptado do questionário de Heisler; Borfe e Burgos (2012). Os entrevistados foram informados sobre os procedimentos da pesquisa, possuindo liberdade para interromper a sua participação em qualquer etapa e, cientes dos riscos e possibilidades, assinaram um Termo de Consentimento Livre e Esclarecido.

Os resultados identificaram os brinquedos, brincadeiras e jogos característicos da cultura infantil da época nas três cidades, bem como constatou detalhes da produção dos brinquedos, como as ferramentas e materiais utilizados. Além disso, o instrumento verificou o tempo e o espaço destinado ao brincar e ao jogar.

A análise dos dados foi realizada a partir da proposta de Bardin (2004) passando pela pré-análise, descrição analítica, onde os dados foram categorizados e as estatísticas foram identificadas, e por fim pela interpretação inferencial. Esta última, segundo Bardin (2004), é o momento em que o pesquisador, apoiado nos materiais de informação da pré-análise e nos resultados encontrados com o instrumento da pesquisa tem condições de refletir melhor sobre o tema e assim apresentar, juntamente com suas reflexões, os resultados da investigação.

\section{Resultados e Discussão}

$\mathrm{Na}$ Tabela 1 são apresentados os resultados obtidos na pesquisa de resgate dos brinquedos tradicionais, através dos questionários aplicados às pessoas com 55 anos ou mais que viveram a infância na Trifronteira. Quando questionados sobre os 
brinquedos que faziam parte da infância, os mais mencionados foram a boneca de pano $(20 \%)$, o carrinho de descida (15\%), a bola (11\%), a boneca de milho (10\%) e o bodoque (7\%). A boneca é um brinquedo presente em todas as culturas e sua transição de ídolos utilizados em rituais para o brinquedo propriamente dito, se deu no Egito, há cinco mil anos (MEFANO, 2005). “Alguns brinquedos nasceram do espírito de emulação das crianças, que as leva a imitar as atitudes dos adultos, reduzindo-os à sua escala" (MEFANO, 2005), como é o caso dos carrinhos.

Analisando os dois brinquedos mais mencionados na tabela 1, a boneca de pano $(20 \%)$ e o carrinho de descida (15\%), e baseado no que aponta Kishimoto (1994), é possível identificar uma representação social implícita do papel do homem e da mulher na sociedade da Trifronteira do período investigado. Sobre o assunto Oliveira (2010, p.52) destaca que na maioria das vezes “a boneca é, para a menina, treino para futura condição de mãe e dona de casa, da mesma forma como comandar o carrinho representa, para o menino, o trabalho fora de casa e a condição de arrimo de família". No período investigado, vale lembrar, o trabalho da mulher estava relacionado quase que exclusivamente ao cuidado do lar e dos filhos, enquanto que ao homem era destinado o trabalho fora de casa de onde provinha o sustento da família. Nesse sentido, o brinquedo muitas vezes significa para a criança a representação da sua realidade e constitui-se como uma forma para construir sua vida social. 


\section{Tabela 1: Brinquedos tradicionais da infância na Trifronteira}

\begin{tabular}{lll}
\hline Brinquedos & Quantidade & Porcentagem \\
& & \\
\hline Boneca de Pano & 15 & $20 \%$ \\
Carrinho de descida & 11 & $15 \%$ \\
Bola (papel, pano, meia, bexiga de porco) & 8 & $11 \%$ \\
Boneca de Milho & 7 & $10 \%$ \\
Bodoque & 5 & $7 \%$ \\
Bolita & 5 & $7 \%$ \\
5 Marias & 3 & $4 \%$ \\
Balanço de Madeira & 3 & $4 \%$ \\
Bicicleta de madeira & 2 & $3 \%$ \\
Cavalinhos de pau & 2 & $3 \%$ \\
Aviãozinho & 1 & $1 \%$ \\
Baralho & 1 & $1 \%$ \\
Boneco de boi com sabugo de milho & 1 & $1 \%$ \\
Brinquedos com corda & 1 & $1 \%$ \\
Carrinho com rodinha de sabugo & 1 & $1 \%$ \\
Carrinho de tampinha & 1 & $1 \%$ \\
Carrocinha & 1 & $1 \%$ \\
Dominó & 1 & $1 \%$ \\
Espada de cana de milho & 1 & $1 \%$ \\
Fogãozinho & 1 & $1 \%$ \\
Pandorga (pipa) & 1 & $1 \%$ \\
Pião & 1 & $1 \%$ \\
Pneu & 1 & $1 \%$ \\
Revolver de madeira & 1 & $1 \%$ \\
\hline Total de respostas & $\mathbf{7 5}$ & \\
\hline
\end{tabular}

Fonte: os autores

Conforme Ariés (2012) na antiguidade não havia distinção entre brinquedos de adultos e brinquedos de criança, assim como não havia distinção entre brinquedos de menina e de menino. Essa distinção, para o autor, só viria a acontecer com a modernidade, com a descoberta da infância. As manifestações lúdicas, sejam elas os brinquedos, brincadeiras ou jogos, encontradas na Trifronteira refletiram essa distinção de práticas quanto ao sexo, principalmente quando nos referirmos aos brinquedos, como no caso das bonecas voltadas às brincadeiras das meninas, e o carrinho de descida voltado às brincadeiras dos meninos. Na presente pesquisa foi possível identificar uma presença maior de distinção entre sexo nos brinquedos e brincadeiras do que distinções entre sexos nos jogos. Nesse sentido, foi possível encontrar práticas corporais que ocorriam conjuntamente entre meninos e meninas da 
época, principalmente no que diz respeito aos jogos como o jogo de peteca, citado tanto por sujeitos da pesquisa homens quanto por mulheres.

Com relação à produção dos brinquedos, constatou-se que $86 \%$ dos brinquedos das crianças da Trifronteira do período investigado eram produzidos artesanalmente, enquanto que somente $14 \%$ tinham origem industrial. No estudo de Heisler, Borfe e Burgos (2012) realizado com pessoas acima de 50 anos do Rio Grande do Sul, também a produção artesanal teve destaque (91,4\%) enquanto que a produção industrial representou $8,4 \%$. Na Tabela 2 foram organizados os aspectos relacionados à produção dos brinquedos nas três cidades analisadas, se artesanal ou industrial e quem eram os responsáveis por essa produção, a fim de identificar realmente quem criava os brinquedos, se era a criança, parentes ou amigos.

\section{Tabela 2: Aspectos gerais da produção dos brinquedos}

\begin{tabular}{lcc}
\hline Responsáveis pela produção do brinquedo & Quantidade & Porcentagem \\
\hline A criança mesma & 20 & $42 \%$ \\
Outros parentes e/ou amigos & 15 & $33 \%$ \\
Os pais & 10 & $21 \%$ \\
Os avós & 1 & $2 \%$ \\
Os irmãos/irmãs & 1 & $2 \%$ \\
\hline Total de respostas & $\mathbf{4 7}$ & $\mathbf{1 0 0 \%}$ \\
\hline
\end{tabular}

Fonte: os autores

O destaque da produção artesanal no período deve-se ao processo de industrialização do brinquedo ter ocorrido, de maneira mais significativa, somente a partir da II Guerra Mundial (1945). Segundo Oliveira (2010), a partir desse período, o uso do uso do plástico foi fator importante de expansão na produção e variedade dos brinquedos, deixando-os mais artificiais na medida em que foram substituindo quase que totalmente os elementos naturais. Nos anos 50 e 60, segundo Ferrari (2010), as mercadorias do comércio da Trifronteira eram oriundas basicamente da produção local, voltadas às necessidades básicas de alimentação, não existia um comércio de brinquedos como ocorre hoje em dia. Desse modo, os brinquedos tinham que ser 
produzidos no local e esta produção ficou na maioria das vezes sob-responsabilidade das próprias crianças (42\%) e demais pessoas como parentes, amigos, avós (58\%) o que demonstra a transmissão de conhecimento (como construir um brinquedo, por exemplo) através da oralidade, conforme Cascudo (1984) característica do brinquedo e do jogo tradicional.

A produção dos brinquedos acontecia a partir da sobra de materiais utilizados nos trabalhos desenvolvidos nas três cidades, como o trabalho de ferreiros, marceneiros, costureiras e agricultores. A extração da madeira, principal material utilizado na confecção dos brinquedos foi durante um longo período, a principal atividade econômica da Trifronteira. Sobre a utilização de determinados materiais para a construção de brinquedos Pereira (2009) justifica que os materiais utilizados na construção de brinquedos artesanais, assim como as técnicas utilizadas na produção, dependiam da circulação de determinados materiais em cada região. Ainda de acordo com a autora, a utilização de materiais variados como porcelana, seda, tintas, entre outros, ficou durante muito tempo, restrito às classes e regiões mais abastadas. No caso do nosso país, a circulação de diferentes mercadorias fazia parte apenas da realidade das capitais.

Na Tabela 3 estão os materiais utilizados na produção dos brinquedos. Benjamin (1985) coloca que o estudo da técnica e do material utilizado na manufatura do brinquedo, observando a forma, o desenho, a cor, o material, permite ao pesquisador penetrar profundamente no mundo dos brinquedos. Com relação aos materiais utilizados na produção de brinquedos na Trifronteira, caracterizam-se por serem resíduos das atividades realizadas nos espaços de trabalho em casa, especialmente carpintaria e costura, e relacionam-se diretamente com as respectivas ferramentas. A madeira, os pregos, as tachinhas e o arame são provenientes das 
atividades de carpintaria, enquanto que tecido, linha, carretéis, botões, barbantes e panos são resíduos das atividades de costura. Materiais que sozinhos não são brinquedos, necessitam da interferência da criança, que aparece como figura essencial no processo de criação dos brinquedos.

\section{Tabela 3: Materiais utilizados na produção de brinquedos na Trifronteira}

\begin{tabular}{ccc}
\hline Materiais Utilizados & Quantidade & Porcentagem \\
\hline Madeira & 19 & $24 \%$ \\
Tecido (Pano) & 12 & $17 \%$ \\
Milho & 10 & $13 \%$ \\
Botão & 7 & $8 \%$ \\
Linha & 5 & $6 \%$ \\
Prego & 5 & $6 \%$ \\
Roupas Velhas & 3 & $5 \%$ \\
Arame & 2 & $2 \%$ \\
Barbantes & 2 & $2 \%$ \\
Carretel de linha & 2 & $2 \%$ \\
Cipó & 2 & $2 \%$ \\
Lata & 2 & $2 \%$ \\
Tachinha & 2 & $2 \%$ \\
Tijolo & 2 & $2 \%$ \\
Areia & 1 & $1 \%$ \\
Carvão & 1 & $1 \%$ \\
Farinha de mandioca & 1 & $1 \%$ \\
Lã de ovelhas & 1 & $1 \%$ \\
Papéis & 1 & $1 \%$ \\
Pena de galinha & 1 & $1 \%$ \\
Pentes de macaco & 1 & $1 \%$ \\
Total de respostas & $\mathbf{8 2}$ & $\mathbf{1 0 0 \%}$ \\
\hline
\end{tabular}

Fonte: os autores

Já na Tabela 4 estão as ferramentas utilizadas na produção dos brinquedos.

Serrote, facão, martelo, eram ferramentas encontradas em casa e de fácil acesso para a criança. $\mathrm{Na}$ época era comum as famílias terem carpintarias em casa para o conserto e até mesmo a confecção de objetos como peças de mobiliário, necessárias para a casa. Assim como os homens trabalhavam na oficina, as mulheres tinham máquinas de costura e todos os apetrechos necessários para a produção ou pequenos consertos de roupas e outras peças de tecido. De acordo com Heisler; Borfe e Burgos (2012), na produção artesanal, o material e a técnica empregados na produção de brinquedos eram uma forma de diálogo entre a criança e os pais, uma forma de aprendizagem do ofício dos mesmos. 
Tabela 4: Ferramentas utilizadas na produção de brinquedos na Trifronteira

\begin{tabular}{lll}
\hline Ferramentas Utilizadas & Quantidade & Porcentagem \\
\hline Martelo & 9 & $30 \%$ \\
Agulha & 7 & $23 \%$ \\
Serrote & 6 & $20 \%$ \\
Facão & 5 & $17 \%$ \\
Tesoura & 2 & $7 \%$ \\
Torno & 1 & $3 \%$ \\
\hline Total de respostas & $\mathbf{3 0}$ & $\mathbf{1 0 0} \%$ \\
\hline
\end{tabular}

Fonte: os autores

Assim como a produção artesanal de brinquedos é voltada para as representações do cotidiano (casas, pessoas, veículos), recriando sob formas lúdicas as diversas representações de pessoas e coisas que convivem no cotidiano (MEFANO, 2005), também a produção dos brinquedos é uma representação das atividades manuais desenvolvidas pelos adultos em casa. A atividade de produzir os próprios brinquedos envolve uma série de habilidades que hoje perdem espaço e acabam sendo esquecidas. Em um primeiro momento tem-se a questão da imaginação, o planejamento e a criatividade em torno da concepção do brinquedo. Na sequência, a habilidade para a execução do mesmo. Ambas atividades são importantes para o desenvolvimento de habilidades, as quais o brinquedo adquirido no comércio não proporciona.

Com relação às brincadeiras e jogos, os entrevistados citaram 27 práticas, apresentadas na Tabela 5. Cada entrevistado foi orientado a citar aquelas que lembrava como pertencentes à sua infância. Através do percentual total das brincadeiras citadas foi possível destacar aquelas mais presentes na cultura infantil da Trifronteira dos anos 50-60. Dessa forma destacaram-se o jogo da peteca (48\%), esconde-esconde (44\%) e caçador (41\%). 


\section{Tabela 5: Brincadeiras e jogos tradicionais da infância na Trifronteira}

\begin{tabular}{ccc}
\hline Brincadeiras e Jogos & Quantidade & Porcentagem \\
\hline Jogo de Peteca & 13 & $48 \%$ \\
Esconde-esconde & 12 & $44 \%$ \\
Caçador & 11 & $41 \%$ \\
Casinha & 10 & $37 \%$ \\
Pega-pega & 8 & $30 \%$ \\
Futebol & 6 & $22 \%$ \\
Gata cega & 6 & $22 \%$ \\
Pula corda & 6 & $22 \%$ \\
Amarelinha & 5 & $18 \%$ \\
Bolita & 4 & $15 \%$ \\
Ciranda & 4 & $15 \%$ \\
Roda cutia & 3 & $11 \%$ \\
Bets & 2 & $7 \%$ \\
Caçar & 2 & $7 \%$ \\
Choca ovo & 2 & $7 \%$ \\
Passa anel & 2 & $7 \%$ \\
Polícia e Ladrão & 2 & $7 \%$ \\
Vôlei & 2 & $7 \%$ \\
Basquete & 1 & $4 \%$ \\
Correr & 1 & $4 \%$ \\
Brincadeira de Comadre & 1 & $4 \%$ \\
Galinho Cego & 1 & $4 \%$ \\
Passa passará & 1 & $4 \%$ \\
Pescar & 1 & $4 \%$ \\
Pula tábua & 1 & $4 \%$ \\
Rebatida & 1 & $4 \%$ \\
Xadrez & 1 & $4 \%$ \\
Total de brincadeiras e jogos & $\mathbf{2 7}$ & $\mathbf{1 0 0 \%}$ \\
\hline & & \\
\hline & 1 & $4 \%$ \\
\hline
\end{tabular}

Fonte: os autores

A grande maioria dos jogos tradicionais popularizados, como amarelinha, bolinha de gude, pião e pipa, chegou ao Brasil por intermédio dos primeiros portugueses (MEFANO, 2005). O jogo da peteca identificado como a prática corporal mais presente na época investigada, é um jogo antigo. Reconhecido como um jogo tipicamente brasileiro que tem sua origem na cultura indígena. A existência desse jogo no arsenal de práticas corporais das crianças da Trifronteira, provavelmente está relacionada a influência indígena na região.

[...] durante aproximadamente os quatro primeiros séculos de colonização espanhola e portuguesa, a atual região fronteiriça não atraiu a atenção dos colonizadores, permanecendo mero ponto de passagem (...) a região era território tradicionalmente ocupado pelas sociedades indígenas, com destaque para guaranis e caingangues (FERRARI, 2010, p. 92). 
O esconde-esconde e o jogo do caçador, destacados nesta pesquisa, são atividades bastante comuns na infância e ocorrem principalmente no contexto da rua. São manifestações lúdicas tipicamente tradicionais que conforme Friedmann (1996), se tornam tradicionais justamente porque são transmitidas de geração em geração, podendo, muitas vezes, mudar a sua forma, ou seja, a sua organização enquanto espaço utilizado, materiais e número de participantes, porém o seu conteúdo permanece o mesmo, constituído pelos interesses lúdicos particulares ligados à manifestação.

$\mathrm{Na}$ infância dos sujeitos entrevistados essas práticas aconteciam na rua. No estudo realizado por Heisler; Borfe e Burgos (2012), o maior percentual de brincadeiras de rua estava relacionado com as crianças que viviam na zona rural, e de acordo com as autoras, pode estar relacionado com os hábitos cotidianos e o modo de vida do campo. Atualmente sabemos da dificuldade de isso acontecer, no entanto, é possível observarmos essas atividades sendo realizadas dentro de condomínios, casas e inclusive na escola.

$\mathrm{Na}$ Tabela 6 estão reunidas as informações sobre o tempo dedicado à brincadeira e ao jogo. De acordo com Staviski; Surdi e Kunz (2013) é necessário refletir sobre o tempo da criança, visto que ele é diferente do tempo do adulto, sendo voltado quase que exclusivamente ao brincar. Maturana e Verden-Zöller (2004) defendem que cada vez mais estamos orientando nossa cultura para a produção e assim para a velocidade, com isso atividades como o brincar têm sido desvalorizadas em detrimento de outras, como o trabalho. 


\section{Tabela 6: Tempo dedicado às brincadeiras e aos jogos}

\begin{tabular}{ccc}
\hline Tempo dedicado à brincadeira & Total de Tempos & Porcentagem \\
\hline Á tarde & 12 & $32 \%$ \\
Final de semana & 10 & $27 \%$ \\
Recreio da escola & 8 & $22 \%$ \\
Antes da escola & 2 & $5 \%$ \\
Sábado & 1 & $2 \%$ \\
Depois da escola & 1 & $2 \%$ \\
Depois do trabalho & 1 & $2 \%$ \\
Dia de semana & 1 & $2 \%$ \\
Quando os pais deixavam & 1 & $2 \%$ \\
Quando os pais saiam & 1 & $2 \%$ \\
Sábado & 1 & $2 \%$ \\
\hline Total de respostas & $\mathbf{3 8}$ & $\mathbf{1 0 0 \%}$ \\
\hline
\end{tabular}

Fonte: os autores

Ao analisar as respostas dos entrevistados é possível perceber que seus cotidianos envolviam o brincar no turno inverso a escola, ou seja, no período da tarde $(31,57 \%)$, nos finais de semana $(26,3 \%)$ e também na escola na hora do recreio (21,5\%). Ao questionar os entrevistados sobre o que eles achavam das brincadeiras e jogos de seus netos, todos mencionaram o uso frequente de tecnologias. Sobre o assunto Paiva e Costa (2015) discutem que uso cada vez mais crescente das tecnologias como computadores, celulares e tablets na infância vem fazendo com que as brincadeiras e jogos tradicionais sejam deixados de lado e com isso também tem surgido problemas no desenvolvimento físico, mental e social.

É evidente que a infância das crianças da Trifronteira dos anos 50 e 60 era diferente da infância da atualidade, não somente pela questão da tecnologia envolvida, mas também devido a outras questões como o desenvolvimento urbano, o crescimento da violência e busca cada vez mais cedo pela preparação profissional. As crianças da Trifronteira, embora muitas envolvidas com o trabalho rural, possuíam um amplo tempo para brincar e jogar no seu dia-a-dia, assim como faziam isso em vários lugares como apresentado na (Tabela 7). 


\section{Tabela 7: Locais dedicados para as brincadeiras e jogos na Trifronteira}

\begin{tabular}{ccc}
\hline Locais dedicados para as brincadeiras e jogos & Quantidade & Porcentagem \\
\hline Pátio & 16 & $34 \%$ \\
Escola & 12 & $25 \%$ \\
Outros* & 12 & $25 \%$ \\
Potreiro & 5 & $11 \%$ \\
Rua & 2 & $5 \%$ \\
\hline Total de respostas & $\mathbf{4 7}$ & $\mathbf{1 0 0 \%}$ \\
\hline
\end{tabular}

Fonte: os autores

A tabela 7 apresenta os locais destinados para as brincadeiras e jogos das crianças da Trifronteira. Identificamos que estas práticas corporais aconteciam em sua maioria no pátio das casas e na escola, principalmente no horário do recreio. Em comparação com o estudo de Heisler; Borfe e Burgos (2012) a pesquisa na Trifronteira destacou a escola como o segundo principal local para a brincadeira e o jogo, representando $25 \%$ dos espaços, enquanto no estudo dos autores há o destaque para o potreiro e os pátios das casas. Dessa forma, é possível supor que a escola, assim como a família também foi, no período, um dos principais locais para a transmissão de brincadeiras e jogos.

\section{Considerações Finais}

Os brinquedos, brincadeiras e jogos tradicionais demonstram as diferentes formas de manifestações culturais de um povo. Isso acontece porque assim como outras produções culturais, elas recebem influências das tradições étnicas que formam a cultura de um local. Basicamente, os brinquedos, as brincadeiras e os jogos tradicionais do Brasil representam a mistura dos costumes e das crenças de sua população bastante miscigenada. No caso da Trifronteira fica evidente a influência da migração gaúcha que acabou por se misturar com a cultura que já havia no local, como a cultura indígena. 
Observou-se que em relação aos brinquedos existia uma grande diferenciação entre os que eram destinados aos meninos e aqueles destinados as meninas, algo fortemente atrelado ao papel social de cada sexo. Porém, foi possível destacar que o mesmo não ocorria com os jogos, como no caso do caçador, onde meninos e meninas jogavam juntos.

Em relação a produção artesanal dos brinquedos, é possível afirmar que era predominante, e se utilizava de resíduos de materiais das atividades produtivas da Trifronteira, bem como materiais naturais, como madeira e cipó. Apesar da produção industrial dos brinquedos já estar estabelecida no Brasil no período, até mesmo com uma grande utilização do plástico, o fato da região estar fora das grandes rotas das capitais fez com que a produção artesanal se estendesse nesse local.

O fato de as três cidades caracterizarem-se por atividades voltadas quase que exclusivamente a agricultura, facilitava para que as crianças brincassem das mais diversas brincadeiras e jogos. O pátio das casas, assim como a escola eram espaços para a troca de conhecimentos sobre as práticas corporais, que eram transmitidas de criança para criança de forma bastante semelhante nos dois países envolvidos.

Os sujeitos entrevistados apontaram que seus netos não conhecem e poucos se interessam em conhecer as práticas corporais de antigamente. Dessa forma, a riqueza das atividades envolvendo as brincadeiras e jogos da região estão se perdendo, principalmente pelo uso constante de tecnologias como o celular e o tablet que vem substituindo o brincar e o jogar. A tecnologia provavelmente criou um abismo que vem dificultando a troca de conhecimentos sobre as brincadeiras e jogos tradicionais, visto que os avós (entrevistados) demonstram aversão à tecnologia, enquanto que os netos demonstram profunda afinidade com a mesma. 
Consideramos que para não se perder a riqueza das diversas culturas presentes na Trifronteira é preciso promover uma convivência social entre todas as gerações. Para isso pode-se pensar no uso das próprias tecnologias utilizadas pelos jovens como uma boa possibilidade de atraí-los para conhecerem as brincadeiras e jogos tradicionais.

\section{Agradecimentos}

Os autores agradecem o apoio e o financiamento da pesquisa pelo Programa Institucional de Bolsas de Iniciação Científica Júnior - PIBIC Jr - do Instituto Federal do Paraná.

\section{REFERÊNCIAS}

ARIÉS, P. História Social da Criança e da Família. Rio de Janeiro: LTC, 2012.

BARDIN, L. Análise de conteúdo. 3. ed. Lisboa: Edições 70, 2004.

BENJAMIN, Walter. Magia e técnica, arte e política. Obras escolhidas. São Paulo: Brasiliense, 1985.

CASCUDO, C. Literatura oral no Brasil. 3. ed. São Paulo: Itatiaia, 1984.

ELKONIN, D. B. Psicologia do jogo. São Paulo: Martins Fontes, 1998.

FERRARI, M. Conflitos e Povoamentos na Zona de Fronteira Internacional Brasil-Argentina: Dionísio Cerqueira (SC), Barracão (PR) e Bernardo de Irigoyen (AR). Florianópolis: Editora UFSC, 2010.

FRANCHI, S. Jogos Tradicionais/Populares como conteúdo da cultura corporal na Educação Física Escolar. Motrivivência, v. 25, n. 40, p.168-177, jun/2013.

FRIEDMANN, A. Brincar: crescer e aprender, o resgate do jogo infantil. São Paulo: Moderna, 1996.

HEISLER, J. B.; BORFE, L.; BURGOS, M. S. Resgate do Brinquedo em suas Transformações e Influências: estudo com pessoas de meia idade e idosos da zona urbana e zona rural do Município de Venâncio Aires e Mato Leitão - RS. Cinergis, v. 13, n. 3, p. 9-20, Jul/Set 2012. 
KISHIMOTO, T. M. Jogo, brinquedo, brincadeira e a educação. São Paulo: Cortês, 1994.

1999.

. Jogos infantis: o jogo, a criança e a educação. 6. ed. Petrópolis: Vozes,

KUNZ, E.; COSTA, A. R. A imprescindível necessidade da criança: "Brincar e SeMovimentar". In: Kunz, E. (Org.). Brincar \& Se-Movimentar: tempos e espaços de vida da criança. Ijuí: Ed. Unijuí, 2015. p. 13-37.

LAVEGA, P. Os jogos tradicionais como patrimônio cultural mundial. In: MARIN, E. C.; RIBAS, J. M. Jogo Cultural e Cultura. Santa Maria: Editora UFSM, 2013. $275-293$ pág.

MARIN, E. C. et al. Jogos tradicionais no Estado do Rio Grande do Sul: manifestação pulsante e silenciada. Movimento. Porto Alegre, v. 18, n. 03, p. 73-94, jul/set de 2012.

MATURANA, H.; VERDEN ZOLLAR, G. Amar e brincar: Fundamentos esquecidos do humano. São Paulo, Editora Palas Athenas, 2004.

MEFANO, L. O design de brinquedos no Brasil: uma arqueologia do projeto e suas origens. 2005. Dissertação (Mestrado) Programa de Pós-Graduação em Design, PUCRio, 2005.

OLIVEIRA, P. S. O que é brinquedo? Coleção Primeiros Passos. São Paulo, Editora Brasiliense, 2010.

PAIVA, N. M. N.; COSTA, J. S. A influência da tecnologia na infância: desenvolvimento ou ameaça. 2015. Disponível em http://www.psicologia.pt/artigos/textos/A0839.pdf Acesso em: 11 dez. 2017.

PEREIRA, Rita Marisa Ribes. Uma história cultural dos brinquedos. Revista Teias, V. 10, n. 20, 2009.

STAVISKI, G.; SURDI, A. C.; KUNZ, E. Sem tempo de ser criança: A pressa no contexto da educação de crianças e implicações nas aulas de educação física. Rev. Bras. Ciênc. Esporte, Florianópolis, v. 35, n.1, p.113-128, jan/mar 2013.

TRIVIÑOS, A. N. S. Introdução à pesquisa em ciências sociais: a pesquisa qualitativa em educação. São Paulo: Atlas, 2012.

\section{Endereço dos Autores:}

Cícera Andréia de Souza

Instituto Federal do Paraná - IFPR

Campus Avançado Barracão

Rodovia BR 116, km 01, s/n

Barracão - PR - 85.700-000

Endereço Eletrônico: cicera.souza@ifpr.edu.br 
Bianca Teles de Moura

Instituto Federal do Paraná - IFPR

Campus Avançado Barracão

Rodovia BR 116, km 01, s/n

Barracão - PR - 85.700-000

Endereço Eletrônico: bianca_teles_2015@outlook.com

Luciano Gularte de Lima

Instituto Federal do Paraná - IFPR

Campus Avançado Barracão

Rodovia BR 116, km 01, s/n

Barracão - PR - 85.700-000

Endereço Eletrônico: lucyanogulartecolombo@gmail.com

Danieli Maehler Nejeliski

Laboratório de Seleção de Materias - LdSM,

Departamento de Design e Expressão Gráfica - UFRGS

Av. Osvaldo Aranha, 99, sala 604, Centro Histórico

Porto Alegre - RS - 90.035-190

Endereço Eletrônico: danielinejeliski@gmail.com 